\title{
PENGARUH MOTIVASI, REWARD DAN PUNISHMENT TERHADAP KINERJA KARYAWAN (STUDI KASUS KLINIK KECANTIKAN PUSPITA BANDAR LAMPUNG)
}

\author{
Selly Suci Marta Sari ${ }^{1}$, Siti Khasanah ${ }^{2}$, Syafiq Pasha ${ }^{3}$, Vicky F Sanjaya ${ }^{4}$ \\ Program StudiManajemenBisnisSyariah, Univeristas Islam NegeriRadenIntan Lampung \\ sellysuci143@gmail.com, sitidoang@gmail.com, syafiqpasha14@gmail.com, \\ vicky@ radenintan.ac.id
}

\begin{abstract}
Abstrak. Penelitianinibertujuanuntukmelihat pengaruh motivasi, reward dan punishment terhadap kinerja karyawan di Puspita. Klinik Kecantikan di kota Bandar Lampung. Penelitian ini menggunakan penelitian kuantitatif deskriptif. Penelitian ini menggunakan 49 responden penelitian yang di ambil sebagai sampel melalui metode purposive sampling. Teknik penggunaan data menggunakan kuesioner. Hasil penelitian menunjukan bahwa reward berpengaruh negatif terhadap kinerja karyawan sedangkan motivasi, dan punishment berpengaruh positif terhadap kinerja karyawan.
\end{abstract}

Kata Kunci : Motivasi, Reward, Punishment, dan Kinerja Karyawan.

\section{THE INFLUENCE OF MOTIVATION, REWARD, AND PUNISHMENT ON EMPLOYEE PERFORMANCE (CASE STUDY OF PUSPITA BEAUTY CLINIC IN BANDAR LAMPUNG)}

\author{
Selly Suci Marta Sari ${ }^{1}$, Siti Khasanah ${ }^{2}$, Syafiq Pasha ${ }^{3}$, Vicky F Sanjaya ${ }^{4}$ \\ Program StudiManajemenBisnisSyariah, Univeristas Islam NegeriRadenIntan Lampung \\ sellysuci143@gmail.com, sitidoang@gmail.com, syafiqpasha14@gmail.com, \\ vicky@ radenintan.ac.id
}

\begin{abstract}
This study aims to see the influence of motivation, reward and punishmenr on employee perfomance at Puspita Beauty Clinic in Bandar Lampung City. This research uses descriptive quantitative research. This study used 49 research respondents who were taken as a sample through purposive sampling method. The techinique of using data using a questionnaire. The result showed that reward had a negative effect to employee performance while motivation and punishment have a positive effect on employee performance.
\end{abstract}

Keywords : Motivation, Reward, Punishment, and employee performance 


\section{PENDAHULUAN}

Dalam era globalisasi seperti sekarang ini persaingan dan kompetisi semakin hari semakin ketat dan luas. Sering kali dengan perkembangan tersebut, masalah yang dialami perusahaan semakin kompetitif karena perusahaan akan menghadapi persaingan dan tantangan. Namun tidak semua perusahaan menerapkan manajemen SDM yang baik, sebagai contoh perusahaan yang menerapkan kualitas SDM yang bermutu yaitu Klinik Kecantikan Puspita Bandar Lampung. Klinik kecantikan Puspita Bandar Lampung sebuah tempat yang memberikan profesional yang berkaitan dengan perawatan dan kecantikan kulit, meliputi proses peremajaan kulit wajah dan memperbaiki berbagai kekurangan kulit.

Manajemen sumber daya manusia (MSDM) merupakan salah satu faktor yang sangat penting dalam suatu perusahaan disamping faktor yang lain seperti modal. Oleh karena itu SDM harus dikelola dengan baik untuk meningkatkan efektivitas dan efesiensi organisasi (hariandja, 2002) Sebagai salah satu penunjang proses operasional di suatu perusahaan didukung dengan sarana dan prasarana serta sumber daya alam yang memadai, akan tetapi tanpa adanya dukungan dari SDM yang berkompetensi dalam kegiatan di suatu perusahaan tidak akan terjalankan dengan baik.

Klinik kecantikan puspita Bandar Lampung tidak hanya meningkatkan kualitas produk kecantikan dan prosesnya. Akan tetapi melakukan peningkatan kualitas kinerja (SDM) menjadi lebih baik dan memiliki mutu yang bagus. Berdasarkan observasi awal yang dilakukan pada karyawan klinik kecantikan puspita pada tanggal 10 Desember yang menjabat sebagai Apoteker yang menyatakan bahwa, selama ini karyawan dituntut agar meningkatkan kinerjanya secara optimal. Klinik Kecantikan Puspita Bandar Lampung juga menerapkan sistem motivasi, reward dan punishment yang cukup ketat. Dan berdasarkan penelitian dengan metode angket (kuesioner) pada tanggal 19 November yang dilakukan oleh peneliti memberikan hasil dan pengaruh bahwa MotivasI, Reward dan Punishment mempengaruhi kinerja karyawan pada klinik Puspita.

Motivasi dapat dipandang sebagai perubahan energi dalam diri seseorang yang ditandai dengan munculnya feeling, dan didahului dengan tanggapan terhadap adanya tujuan. Seperti yang dikemukakan oleh mangkunegara (2009:61) Motivasi merupakan kondisi atau energi yang menggerakan diri karyawan yang terarah atau tertuju untuk mencapai tujuan organisasi perusahaan. sikap mental karyawan yang positif terhadap situasi kerja itulah yang memperkuat motivasi kerjanya untuk mencapai kinerja yang maksimal. Tiga unsur yang merupakan kunci dari motivasi, yaitu upaya, tujuan organisasi dan kebutuhan. Yang selama ini pemberian reward sudah sesuai dengan peraturan yang telah ditetapkan. Sehingga pemberiaan penghargaan atau bonus pada karyawan yang berprestasi dan teladan tersalurkan dengan baik, karena manajemen klinik kecantikan puspita sangat memperhatikan para karyawan, maka berdampak baik pada produktivitas kerja karyawan klinik kecantikan puspita.

Reward adalah sesuatu yang kita berikan kepada seseorang karena dia melakukan sesuatu, Sesuatu tersebut wajar sebagai apresiasi, sebagai ungkapan terima kasih dan perhatian kita (wijarnako,2005:30). Reward yang telah ditetapkan tersebut diantaranya melalui pemberian pujian bagi karyawan dari atasan ataupun konsumen, pemberian kompensasi, penambahan bonus, dan pemberian hadiah bagi karywan yang berprestasi yang telah memenuhi syarat 
dan kriteria tertentu yang telah diterapkan. Sama halnya dengan punishment yang telah ditetapkan oleh klinik kecantikan puspita diantaranya melalui teguran dari atasan ke karyawan yang telah dirasa lalai dalam melakukan kewajiban bekerja, melalui surat peringatan, sanksi bagi karyawan yang lalai dalam bekerja. Oleh karena itu punishment ysng diberikan harus bersifat pedagogies, yaitu memperbaiki dan mendidik kearah yang lebih baik. Pemberian reward dan punishment yang baik dan benar akan memberikan motivasi kepada karyawan untuk lebih meningkatkan kinerjanya dan perusahaan dapat mencapai tujuan secara keseluruhan.

Klinik kecantikan puspita menerapkan sistem reward dan punishment secara ketat sebagai upaya untuk memotivasi dan mendisiplinkan kinerja karyawan agar lebih meningkatkan kinerjanya. Dari hal tersebut peneliti ingin pengetahui efek yang ditimbulkannya dari adanya motivasi reward dan punishment terhadap karyawan klinik kecantikan puspita.

Berdasarkan pemersalahan diatas maka, peneliti mengambil judul ??Pengaruh Motivasi Reward dan Punishment terhadap Kinerja Karyawan di Klinik Kecantikan Puspita.

\section{TINJAUAN PUSTAKA DAN PENGEMBANGAN HIPOTESIS \\ Pengaruh Motivasi terhadap Kinerja Karyawan \\ Menurut (Thoha, 2011) dan} (Pebriani dan Santosa, 2019) menyatakan. Motivasi merupakan salah satu unsur pokok dalam perilaku seseorang. Dimana seseorang akan dapat melakukan kegiatan apabila ada keinginan yangtimbul dari dalam diri orang tersebut. Sedangkan (Guruh Dwi 2020) mengatakan bahwa motivasi adalah sebagai salah satu faktor pendorong prestasi kerja karyawan, yang harus mendapat perhatian khusus dari pimpinan jika menghendaki kinerja karyawannya meningkat sehingga tujuan yang diharapkan bisa tercapai. Berdasarkan penelitian sebelumnya dikatakan oleh Suarni dan Nyoman (2020) dalam jurnalnya berdasarkan hasil analisis penelitian tentang ?Pengaruh Gaya kepemimpinan dan Motivasi terhadap Kantor Camat? menyatakan Ada pengaruh yang positif dan signifikan secara parsial antara motivasi terhadap kinerja karyawan. Menurut Merry S (2019) Hasil penelitiannya dalam jurnal menunjukan bahwa motivasi memberikan kontribusi yang positif terhadap kinerja karyawan dan salah satu variabel yang mempengaruhi kinerja karyawan sehingga dibutukan motivasi yang baik dari seorang pemimpin.

Hipotesis 1 :Motivasi berpengaruh positif signifikan terhadap Kinerja Karyawan.

\section{Pengaruh Reward terhadap Kinerja Karyawan}

Menurut Purnama, (2015) menyatakan bahwa reward merupakan sebuah bentuk pengakuan kepada suatu prestasi tertentu yang diberikan dalam bentuk material dan non material yang diberikan oleh pihak organisasi atau lembaga kepada individu atau kelompok pegawai agar mereka dapat bekerja dengan motivasi yang tinggi dan berprestasi dalam mencapai tujuan-tujuan organisasi.Simamora (2004) juga menyatakan reward adalah insentif yang mengaitkan bayaran atas dasar untuk dapat meningkatkan produktivitas para karyawan guna mencapai keunggulan yang kompetitif. Menurut Aktar (2012) Reward adalah suatu elemen penting untuk memotivasi karyawan untuk berkontribusi menuangkan ide inovasi yang paling baik untuk fungsi bisnis yang lebih baik dan meningkatkan kinerja perusahaan baik secara financial dan non-financial. Menurut Natasya Michelle Putri Kentjana dan Piter Nainggolan (2018) Reward berpengaruh negatif terhadap kinerja 
karyawan BCA. Hasil pengujian yang dilakukan menggunakan Warp PLS 3.0 menunjukkan nilai signifikansi sebesar 1.14 (<0.05). Hal ini menunjukkan bahwa reward yang diterima karyawan baik itu reward intrinsik maupun reward ekstrinsik belum dapat mempengaruhi kinerja karyawan BCA secara signifikan. Dan pada penelitian Suak dkk (2017) lainnya memperoleh bahwa penghargaan (reward) berpengaruh positif tidak signifikan terhadap kinerja karyawan. Tinggi ataupun rendahnya kinerja karyawan tidak hanya dipengaruhi oleh penghargaan (reward) namun terdapat faktor lainnya yaitu hukuman atau sanksi (punishment).Anwar \& Dunija (2016) berdasarkan Pengujian hipotesis secara simultan reward tidak mempunyai pengaruh positif yang signifikan terhadap disiplin kerja karyawan PT. $14.9 \%$, sedangkan sisanya $85.1 \%$ dipengaruhi oleh variabel lain. Secara parsial reward tidak berpengaruh signifikan terhadap disiplin kinerja karyawan.

Hipotesis 2 :Reward berpengaruh negatif terhadap kinerja karyawan

\section{Pengaruh Punishment terhadap Kinerja Karyawan}

Menurut (Eko Septian 2020) mengatakan Punishment adalah hukuman yang diberikan karena adanya pelanggaran terhadap aturan yang berlaku. Dalam perusahaan saksi diberikan kepada karyawan yang lalai atau melakukan kesalahan yang dapat merugikan perusahaan. Irmayanti (2013), punishment adalah sebuah cara untuk mengarahkan sebuah tingkah laku agar sesuai dengan tingkah laku yang berlaku secara umum. Mangkunegara (2013) Punishment didefinisikan sebagai tindakan menyajikan konsekuensi yang tidak menyenangkan atau tidak diinginkan sebagai hasil dari dilakukanya perilaku tertentu. Penelitian sebelumnya dikatakan oleh Eko Septian Dymastara (2020) Punishment berpengaruh signifikan terhadap Kinerja Karyawan pada Pada PT. Sandabi Indah Lestari Bengkulu Utara. Menurut Vallery G.E Nompo dan Merinda H.Ch Pandowo (2020) Punishment secara parsial berpengaruh terhadap Kinerja Karyawan di PT.Pegadaian (Persero) Kanwil V Manado. Dan dikatakan oleh Winda Sri Astuti1 , Herman Sjahruddin , dan Susenohadi Purnomo (2018) menunjukkan bahwa punishment berpengaruh positif signifikan terhadap kinerja karyawan.

Hipotesis 3 : Punishment berpengaruh positif signifikan terhadap Kinerja Karyawan.

\section{PENGARUH MOTIVASI}

Hakim (2006) mendefinisikan Motivasi merupakan dorongan upaya dan keinginan yang di dalam diri manusia yang mengaktifkan, memberi daya serta mengarahkan perilakunya untuk melaksanakan tugas dan tanggung jawab dalam lingkup pekerjaannya.

Teori motivasiyang paling terkenal adalah hirarki kebutuhan yang diungkapan Abraham Maslow. Hipotesisnya mengatakan bahwa di dalam diri semua manusia bersemayam lima jenjang kebutuhan (Maslow, dalam Robbins, 2006) Terdapat 5 indikator untuk pengaruh motivasi yaitu:

1. Fisiologis: antara lain rasa lapar, haus, perlindungan (pakaian danperumahan), seks, dan kebutuhan jasmani lain.

2. Keamanan: antara lain keselamatan dan perlindungan terhadap kerugian fisik dan emosional.

3. Sosial: mencakup kasih sayang, rasa memiliki, diterima baik, dan persahabatan.

4. Penghargaan: mencakup faktor penghormatan diri seperti harga diri, otonomidan prestasi serta faktor penghormatan dari luar 
seperti

misalnya

status,pengakuandan perhatian.

5. Aktualisasi diri: dorongan untuk menjadi seseorang/sesuatu sesuai ambisinyayang mencakup pertumbuhan, pencapaian potensi, dan pemenuhan kebutuhan

\section{PENGARUH REWARD}

Wijanarko (2005) menjelaskan Reward adalah sesuatu yang kita berikan kepada seseorang karena dia melakukan sesuatu. Sesuatu tersebut wajar sebagai apresiasi, sebagai ungkapan terima kasih dan perhatian kita.Reward merupakan suatu bentuk apresiasi usaha untuk mendapatkan tenaga kerja yang profesional sesuai dengan tuntutan jabatan diperlukan suatu pembinaan yang berkeseimbangan, yaitu suatu usaha kegiatan perencanaan, pengorganisasian, penggunaan, dan pemeliharaan tenaga kerja agar mampu melaksanakan tugas dengan efektif dan efisien. Sebagai langkah nyata dalam hasil peembinaan maka diadakan pemberian reward pegawai yang telah menunjukan prestasi kerja yang baik Handoko (2003). Terdapat 4 Indikator yang mempengaruhi reward yaitu:

1. Gaji dan bonus merupakan tambahan dari upah yang diterima karyawan setiap bulannya karena kinerjanya bagus dan mencapai target tertentu.

2. Kesejahteraan untuk meningkatkan kesetiaan dan keterikatan karyawan kepada karyawan lainnya. dengan tujuan memberikan ketenangan dan pemenuhan kebutuhan bagi karyawan, memotivasi gairah kerja disiplin dan produktifitas kerja bagi karyawan.

3. Pengembangan karir diartikan sebagai kegiatan kepegawaian guna membantu para karyawan merencanakan karir masa depan ditempat kerja mereka bekerja.
4. Penghargaan psikologis dan sosial, merupakan penghargaan intrinsik yang datang dari dalam diri seseorang, seperti pujian, sanjungan, dan ucapan selamat. Sedangkan penghargaan sosial berkaitan dengan pujian dan pengakuan diri yang diperoleh baik dari dalam maupun luar organisasi, dapat berupa materi finansial dan piagam penghargaan.

\section{PENGARUH PUNISHMENT}

Menurut Irmayanti

(2013) punishment adalah sebuah cara untuk mengarahkan sebuah tingkah laku agar sesuai dengan tingkah laku yang berlaku secara umum. Punishment adalah sebuah cara untuk mengarahkan sebuah tingkah laku agar sesuai dengan tingkah laku yang berlaku secara umum. Dalam hal ini, hukuman akan diberikan ketika sebuah tingkah laku yang tidak diharapkan ditampilkan oleh orang yang bersangkutan atau orang yang bersangkutan tidak memberikan respon atau tidak menampilkan sebuah tingkah laku yang diharapkan. Terdapat 4 Indikator yang mempengaruhi punishment yaitu:

1. Usaha meminimalisir kesalahan yang akan terjadi. Jika dalam suatu perusahaan atau organisasi karyawan harus bisa meminimalisir kesalahan yang dibuat dalam berkerja, karena jika karyawan tersebut terus-menerus melakukan kesalahan perusahaan tersebut akan memberikan punishmentnya.

2. Adanya hukuman yang lebih berat bila kesalahan yang sama dilakukan. Hukuman yang diberikan oleh atasan semata-mata akan membuat karyawan jera melakukan kesalahan, tetapi jika karyawan tersebut melakukan kesalahan yang sama maka dilakukan atasan akan memberikan hukuman yang lebih berat. 
3. Hukuman diberikan dengan adanya penjelasan. Seseorang karyawan perlu menanyakan kejelasan kepada atasanya, apa hukumannya jika karyawan tersebut melakukan kesaalahan ringan dan apa hukumnya jika karyawan melakukan kesalahan yang berat.

4. Hukuman segera diberikan setelah terbukti adanya penyimpangan. Dengan adanya pengawasan kepada karyawan atasan bisa memantau para karyawan yang berkerja pada perusahaan tersebut, jika karyawan tersebut melakukan kesalahan dan terbukti melakukan kesalahan tersebut maka atasan langsung memberikan hukuman yang sesuai dengan kesalahan tersebut.

\section{PENGARUH KINERJA KARYAWAN}

menurut Veithzal Rivai dan Ella Jauvani (2010) menyatakan bahwa "Kinerja merupakan perilaku nyata yang ditampilkan setiap orang sebagai prestasi kerja yang dihasilkan oleh karyawan sesuai dengan perannya dalam perusahaan." kinerja dapat diartikan sebagai suatu hasil kerja atau pencapaian prestasi kerja seorang pegawai dalam melaksanakan tugasnya sesuai dengan wewenang dan tanggungjawab masingmasing yang berkaitan dengan tujuan strategis organisasi kepuasan konsumen dan memberikan kontribusi ekonomi. Terdapat 4 Indikator yang mempengaruhi kinerja karyawan yaitu:

kinerja karyawan dengan indikator :

1. Kualitas kerja yaitu seberapa baik karyawan melakukan pekerjaannya.

2. Kuantitas kerja yaitu seberapa lama karyawan melakukan pekerjaannya dalam satu harinya.

3. Pelaksanaan tugas yaitu seberapa jauh karyawan dapat menyelesaikan dengan akurat atau tanpa kesalahan.

4. Tanggung jawab atas pekerjaan yaitu kesadaran akan pekerjaan yang diberikan kepada karyawan dalam melaksanakan pekerjaan.

\section{METODE PENELITIAN}

Penelitian ini menggunakan Metode Kuantitatif dengan metode pengukuran data kuantitatif dan statistika objektif melalui perhitungan ilmiah yang berasal dari sampel Kinerja Karyawan di Klinik Kecantikan Puspita Lampung yang diminta menjawab sejumlah pertanyaan dalam kuesioner untuk menentukan frekuensi dan persentase tanggapan mereka.

Teknik analisis data yang digunakan dalam penelitian ini menggunakan analisis partial least square (PLS) dari data yang disajikan adalah seluruh informasi data yang sudah didapat.

PLS merupakan suatu teknik statistik multivariate yang bisa untuk menangani banyak variabel eksplanatori sekaligus diolah menggunakan aplikasi SmartPLS, dan data yang dihasilkan berupa tulisan, tabel, dan grafik agar memudahkan dalam menganalisis data untuk mendapatkan hasil yang sistematis

\section{PEMBAHASAN}

\section{Isi Hasil dan Pembahasan}

Berdasarkan hasil uji yang dilakukan terdapat 49 responden yang mengisi kuesioner mengenai Pengaruh Motivasi, Reward dan Punishment terhadap Kinerja Karyawan.

Diantaranya perempuan berjumlah 28 orang dan laki-laki berjumlah 21 orang dengan usia 19 sampai 45 tahun. Bekerja sebagai karyawan/karyawati di klinik puspita Lampung. 
Outer loadings adalah tabel yang berisi loading factor untuk menunjukkan besar korelasi antara indikator dengan variabel laten. Nilai loading factor harus $>0,7$ maka dikatakan valid. Output outer loadings dapat diperoleh dari PLS Algorithm Report SmartPLS.

\section{Hasil Uji Validitas dan Reabilitas}

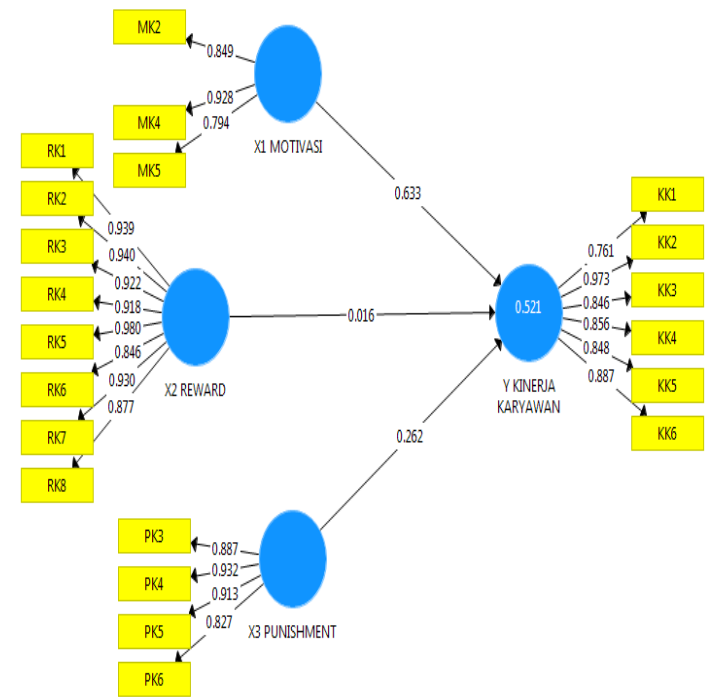

Gambar 1. Model Penelitian

Keterangan:

MK :Motivasi Kinerja

RK :Reward Kinerja

PK :Punishment Kinerja

KK :Kinerja Karyawan

HasilUjiValiditasdanReabilitas

Sebelum uji T- statistik, terlebih dahulu di lakukan uji Validitas dan Reabilitas terhadap data yang akan di teliti. Untuk menghindari data-data yang tidak valid yang dapat mengakibatkan terjadinya ketidak optimalan dalam penelitian.

Berdasarkan dari hasil Validitas dan Reabilitas yang kami lakukan terdapat beberapa item kuisioner yang gugur karena tidak memenuhi batas standar nilai loading factor sehingga perlu di eliminasi ulang. Pada Variabel X1 (Pengaruh Motivasi) terdapat 2 item yang gugur dan tidak memenuhi standar dari 5 item, sedangkan pada X2 (Pengaruh Reward) semua item memenuhi standard dari 8 item sedangkan pada X3 (Punishment) terdapat 2 item yang gugur dan tidak memenuhi standard dari 6 item. dan pada Y (Kinerja Karyawan) keenam pertanyaan memenuhi standard. Selanjutnya dilakukan pengujian ulang terhadap validitas sehingga didapat semua indikator memiliki hubungan positif terhadap masing-masing variabel laten dan semua nilai item indikator berada diatas standar nilai loading factor diatas $>0.7$.

Hasil tersebut menunjukan bahwa penggunaan masing-masing indikator tersebut dinyatakan mampu mengukur variabel laten secara tepat.

Table 1.HasilUjiValiditas

\begin{tabular}{lcccc}
\hline Item & $P M$ & $P R$ & $P P$ & $K K$ \\
$M K 2$ & 0.849 & & & \\
$M K 4$ & 0.928 & & & \\
$M K 5$ & 0.794 & & & \\
$R K 1$ & & 0.939 & & \\
$R K 2$ & & 0.940 & & \\
& & & & \\
$R K 3$ & & 0.922 & & \\
$R K 4$ & & 0.918 & & \\
$R K 5$ & & 0.980 & & \\
$R K 6$ & & 0.846 & & \\
$R K 7$ & & 0.930 & & \\
$R K 8$ & & 0.877 & & \\
$P K 3$ & & & 0.887 & \\
$P K 4$ & & & 0.932 & \\
$P K 5$ & & & 0.913 & \\
$P K 6$ & & & 0.827 & \\
$K K 1$ & & & & 0.761 \\
$K K 2$ & & & & 0.973 \\
\hline
\end{tabular}

Table 2.HasilUjiReabilitas

Cronbac rho Composit $A V$.

$\begin{array}{lllll}\text { MOTIVASI } & 0.822 & 0.8 ! & 0.893 & 0.7 \\ \text { REWARD ( } & 0.974 & 0.9 & 0.978 & 0.8 \\ \text { PUNISHME } & 0.913 & 0.9: & 0.939 & 0.7 \\ \text { KINERJA K } & 0.931 & 0.9: & 0.946 & 0.7\end{array}$


Table 3.

\section{Path Coefficience}

\begin{tabular}{|c|c|c|c|c|}
\hline & Samk & $\begin{array}{l}\text { Rata } \\
- \text { Rata }\end{array}$ & Standar $L$ & $\begin{array}{l}\text { TSta PVG } \\
(\mid 0 S 7\end{array}$ \\
\hline $\begin{array}{l}\text { Pengarul } \\
>\text { Kinerj }\end{array}$ & 0.633 & 0.633 & 0.096 & 6.6300 .00 \\
\hline $\begin{array}{l}\text { Pengarul } \\
>\text { Kiner }\end{array}$ & 0.016 & 0.046 & 0.129 & 0.1240 .90 \\
\hline $\begin{array}{l}\text { Pengarul } \\
>\text { Kinerj }\end{array}$ & 0.262 & 0.239 & 0.102 & 2.5600 .01 \\
\hline
\end{tabular}

Berdasarkan hasil analisis, dapat disimpulkan bahwa hasil dari pengujian hipotesis dalam penelitian ini adalah sebagai berikut :

Hipotesis 1 : Motivasi berpengaruh positif signifikan terhadap Kinerja Karyawan.

Berdasarkan hasil output table 3 , nilai signifikansi $<0,05$ dan dari pengujian yang telahdilakukanbahwaMotivasiberpengaruh positifdan signifikan terhadapkinerjakaryawan. Dengannilai Pvalue $(0.000>0.05)$, nilai $\mathrm{T}$ statistic untuk Motivasi terhadap Kinerja Karyawan (KK) sebesar 6,630 > T table $(1,67)$. Dengan demikian Hipotesis pertama diterima.

Hipotesis 2 : Reward berpengaruh negatif terhadap Kinerja Karyawan.

Berdasarkanhasil output table 3, nilai signifikansi $<0.05$ dan dari pengujian yang telah dilakukan bahwa Reward berpengaruh positif terhadap Kinerja Karyawan. Dengannilai P-value (0.901 > $0.05)$, nilai $\mathrm{T}$ statistic untuk Reward terhadap Kinerja Karyawan (KK) sebesar 0,124> $\mathrm{T}$ table $(1,67)$. Dengan demikian Hipotesis dua ditolak.

Hipotesis 3 : Punishment berpengaruh positif signifikan terhadap Kinerja Karyawan.
Berdasarkanhasil output table 3, nilai signifikansi $<0.05$ dan dari pengujian yang telah dilakukan bahwa Punishment berpengaruh positif dan signifikan terhadap Kinerja Karyawan. Dengannilai P-value $(0.011>0.05)$, nilai $\mathrm{T}$ statistic untuk Punishment terhadap Kinerja Karyawan (KK) sebesar2,560 >T table $(1,67)$. Dengan demikian Hipotesis tiga diterima.

\section{KESIMPULAN}

Berdasarkan hasil pengujian yang telah dilakukan di atas, dapat disimpulkan bahwa pengaruh Motivasi, Reward, Punishment berpengaruh signifikan dan positif terhadap Kinerja karyawan, semakin adanya Motivasi, Reward dan Punishment yang berkualitas maka Kinerja karyawan akan semakin tinggi. Hal serupa dengan pengaruh motivasi, reward, dan punishment berpengaruh positif dan signifikan terhadap Kinerja karyawan, dimanamotivasi yang diberikan oleh atasansangat berpengaruh positif dan signifikan yang tinggi dikarenakan adanya harga yang ditawarkan oleh penyedia jasa atau terhadap kinerja karyawan. Begitu pula dengan Reward dimana para karyawan setuju dengan adanya sistem reward yang diberikan oleh perusahaan dan memberikan persepsi yang cukup baik terhadap sistem raward yang diterimanya untuk lebih bertanggung jawab dalam melaksanakan pekerjaannya dan Punishment juga sangat berpengaruh positif dan signifikan terhadap kinerja karyawan dimana penerapan dalam klinik puspita Bandar Lampung sudah cukup baik, sehingga ditingkatkan pun tidak akan berpengaruh. Dapat disimpulkan bahwa variabel yang dipilih oleh penelitian sangatberpengaruh terhadap kinerja karyawan. Maka dapat disimpulkan penelitian ini adalah pengaruh motivasi reward dan punishment 
terhadap kinerja karyawan. Kinerja adalah hasil kerja secara kualitas dan kuantitas yang dapat dicapai oleh seorang karyawan dalam melaksanakan tugas sesuai dengan tanggung jawab yang diberikan. Agar kinerja karyawan selalu konsisten maka harus mengidentifikasi faktor-faktor yang mempengaruhi kinerja antara lain adalah motivasi kerja, pemberian reward dan melakukan hukuman/pelanggaran.

\section{SARAN}

Reward dan Punishment adalah dua bentuk metode untuk memotivasi karyawan dalam bekerja. Maka diharapkan bagi pimpinan atau manajemen klinik Puspita Bandar Lampung agar dapat memperhatikan reward dan punishment, juga mengevaluasi bentuk reward dan punishment seperti apa yang bisa mempengaruhi dalam upaya meningkatkan kinerja karyawan di Klinik Kecantikan Puspita.

Perlu dilakukan bagi Klinik Puspita Bandar Lampung untuk melakukan pendekatan yang berbeda dalam hal memberikan reward kepada karyawan agar dapat meningkatkan kinerja karyawan dan semangat kerja.

Peneliti selanjutnya kiranya dapat mengembangkan penelitian dengan meneliti menggunakan variabel-variabel lain yang ada diluar penelitian ini atau dengan mengkombinasikan variabel yang terdapat dalam penelitian ini dengan variabel lain untuk dijadikan bahan penelitian di Klinik Puspita.

\section{DAFTAR PUSTAKA}

(Permatasari \& Supiyan, 2020)Nurcahyani, N., \& Adnyani, I. (2016). PENGARUH KOMPENSASI DAN MOTIVASI TERHADAP KINERJA KARYAWAN DENGAN KEPUASAN KERJA SEBAGAI VARIABEL INTERVENING. $E$ -

\section{Jurnal Manajemen Universitas Udayana.}

Permatasari, R. J., \& Supiyan, D. (2020). Jurnal Ekonomi Balance Jurnal Ekonomi Balance. Jurnal Ekonomi Efektif, 2(3), 423.

(Nurcahyani \& Adnyani, 2016)Nurcahyani, N., \& Adnyani, I. (2016). PENGARUH KOMPENSASI DAN MOTIVASI TERHADAP KINERJA KARYAWAN DENGAN KEPUASAN KERJA SEBAGAI VARIABEL INTERVENING. $E$ Jurnal Manajemen Universitas Udayana.

(Rismayadi \& Maemunah, 2016)Rismayadi, B., \& Maemunah, M. (2016). Pengaruh Motivasi Kerja, Kepemimpinan dan Budaya Organisasi Terhadap Kepuasan Kerja Karyawan serta Dampaknya pada Kinerja Perusahaan (Studi kasus pada PT. Concord Indonesia). Jurnal Manajemen \& Bisnis Kreatif. https://doi.org/10.36805/manajemen.v $2 \mathrm{i} 1.181$

(Astuti et al., 2018)Astuti, W. S., Sjahruddin, H., \& Purnomo, S. (2018). Pengaruh Reward Dan Punishment Terhadap Kinerja Karyawan Dengan Kepuasan Kerja Sebagai Variabel Inervening. Organisasi Dan Manajemen, 1(1), 31-46.

(Pramesti et al., 2019)Pramesti, R. A., Sambul, S. A. P., \& Rumawas, W. (2019). Pengaruh Reward Dan Punishment Terhadap Kinerja Karyawan KFC Artha Gading. Jurnal Administrasi Bisnis, 9(1), 57. https://doi.org/10.35797/jab.9.1.2019. 23557.57-63

(Wayan Rekayana Yasa Putra, Anak 
Agung Putu Agung, 2019)Wayan Rekayana Yasa Putra, Anak Agung Putu Agung, P. K. (2019). Pengaruh Gaya Kepemimpinan Dan Motivasi Terhadap Disiplin Kerja Dan Kinerja Karyawan Pada Koperasi Pegawai Bina Sejahtera Kabupaten Badung. Jurnal Sains, Akuntansi Dan Manajemen (JSAM), 1(4), 576-595.

(Hidayat \& Ferdiansyah, 2011)Hidayat, C., \& Ferdiansyah, F. (2011). Pengaruh Motivasi dan Kepuasan Kerja terhadap Kinerja Karyawan. Binus Business Review, 2(1), 379. https://doi.org/10.21512/bbr.v2i1.114 4 